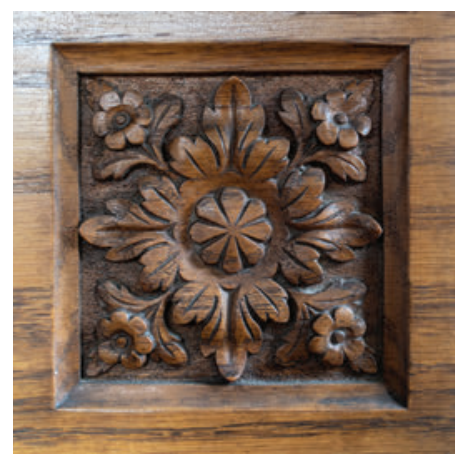

\title{
A Virtuous Circle of Scholarship
}

\section{Gerald Beasley}

Carl A. Kroch University Librarian

Tf I read three books every week this year, all published by 1 Cornell University Press, I will keep up with its current rate of production. But I will still be leaving untouched its legacy of nearly 7,000 titles published over the last 150 years.

Cornell University Library has always had a strong relationship with Cornell University Press. As you will read in Karen Laun's excellent history, in 1869 Daniel Willard Fiske was the first university librarian as well as the first director of the press. He was also a professor of North European languages and established by bequest a series published by Cornell relating to Iceland and the Icelandic Collection he had founded. Its latest volume, Islandica 59 (2016), can be purchased in print from the press or downloaded free of charge from the library's online institutional repository, eCommons. Perhaps like me you are unsure which format you would prefer but grateful that you have a choice. 
Much has changed and much has stayed the same at Cornell since 1869 . The title of university librarian is now named in honor of Carl A. Kroch, a legendary bookseller, library supporter, and Cornell alumnus, who died in I999. I was appointed Carl A. Kroch University Librarian in August $20 I 7$ and inherited the press from the vice provost for international affairs on January I, 20I8. I think press director Dean Smith's new reporting relationship to me suits us both very well. Certainly, academic libraries have always depended heavily on the expertise and output of university presses. Not only do the latter provide much of the content that libraries then make available, but their work also guides an understanding of what is attracting the attention of experts within any particular discipline. This in turn inspires the library's collection development initiatives. Hopefully the authors in question have found useful material for their research in libraries and archives. In any case, the virtuous circle is complete when an author's study is acquired by the library and itself becomes the source for new scholarship.

There are many other reasons why the anniversary of Cornell University Press should be celebrated. One is reputation. It is not easy to identify reliable knowledge by searching for it in the wide world of the web. A book from CUP, on the other hand, has undergone a rigorous process of review before it ever arrives in your hand or on your device. It is a quality product. Thanks to its reputation, built over a century and a half, you know a lot about its contents even before you begin reading. In a world increasingly vulnerable to half-truths and misinformation, that in itself is surely worth celebrating. 
Cornell University Press, Est. 1869

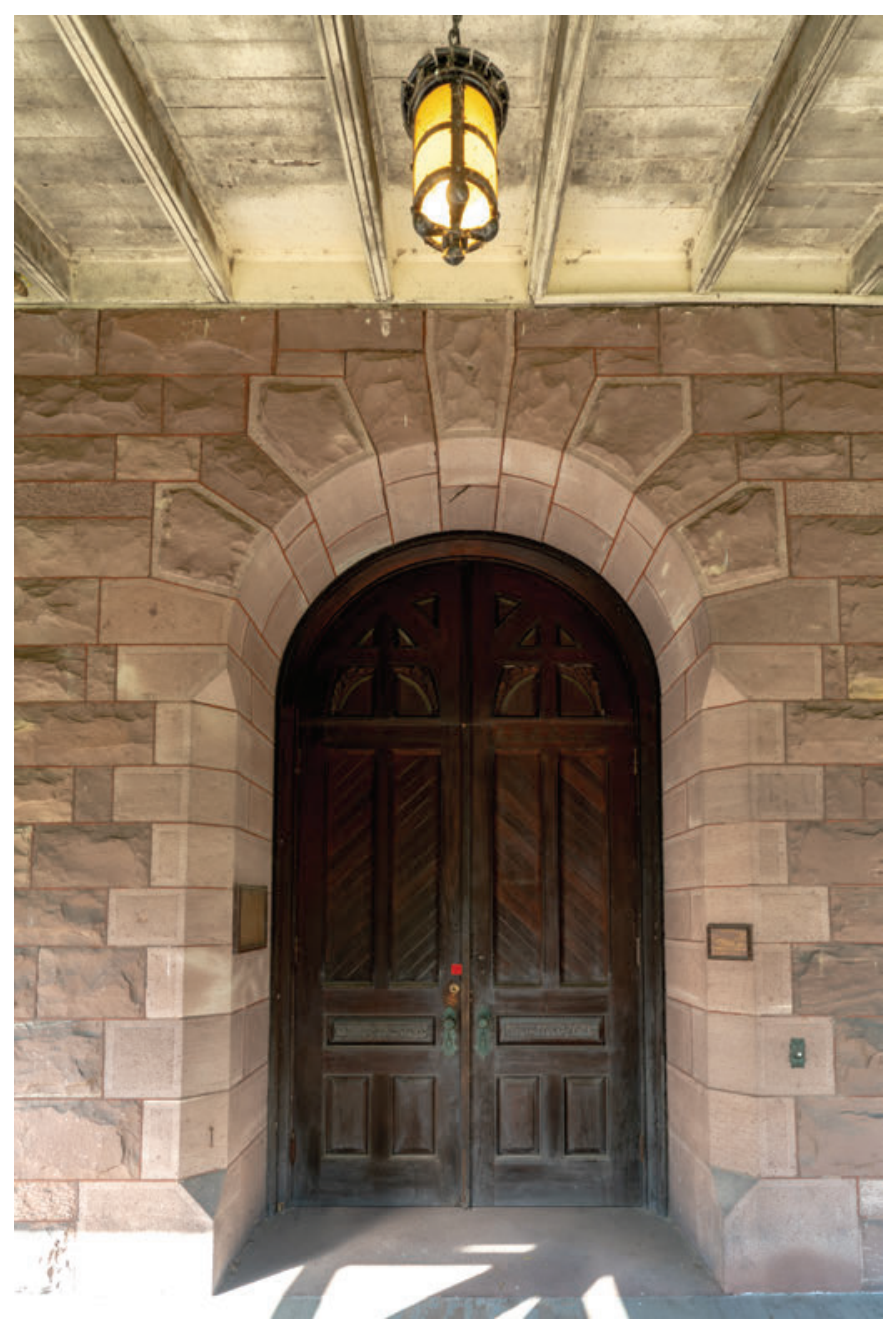


